\title{
The Enlightenment of American Subprime Mortgage Crisis to Financial Supervision in China
}

\author{
Shao Wenya ${ }^{1, a}$, Wu Lili ${ }^{2, b^{*}}$ \\ 1 GuiZhou University of Finance and Economics, Guiyang, Guizhou, China \\ ${ }^{2}$ GuiZhou University of Finance and Economics, Guiyang, Guizhou, China \\ a17826629079@163.com \\ b*1162602625@qq.com
}

\begin{abstract}
Since March 2007, the subprime crisis has had a huge impact on the world economy. Therefore, the Enlightenment from the subprime mortgage crisis can also help us to do some prevention or reduce some losses when the crisis comes. Therefore, this article analyzes the enlightenment to our country's financial supervision from three aspects: Consumer Awareness, financial institutions and supervision authorities, in the hope of providing some ideas.
\end{abstract}

Keywords: subprime mortgage crisis, financial regulation, financial derivatives

\section{美国次贷危机对我国金融监管的启示}

\author{
邵文雅 ${ }^{1, a}$, 伍立力 $2, \mathrm{~b}^{*}$
}

\author{
'贵州财经大学, 贵阳, 贵州, 中国 \\ 2 贵州财经大学, 贵阳, 贵州, 中国 \\ a17826629079@163.com \\ b*1162602625@qq.com
}

\section{摘要}

始于 2007 年 3 月的次贷危机，对世界各国的经济都造成了巨大的影响。因此，从次贷危机中得到的启示也可 以帮助我们在危机到来的时候做一些预防或减少一些损失。次贷危机是由各方的共同作用而形成的, 每一方都 有不可推卸的责任，因此，本文从消费者意识、金融机构和监管当局三方面来分析对我国金融监管的启示，以 期能够提供一些想法。

关键词: 次贷危机；金融监管；金融衍生品；消费意识

\section{1. 引言}

次级按揭贷款危机简称次贷危机，它是由于贷款 给资信条件较差的人的而产生的危机。2001-2003 年, 美国利率连续下调, 利率低促使房地产市场繁荣, 房 地产市场泡沫逐渐形成, 资信条件差的人对于贷款机 构来说是高风险客户, 还款能力低, 不止个人, 企业 也能够在低利率的条件下获得大量贷款。2005 年第二 季度, 住房市场大幅降温, 利率上调, 民众还不上贷, 银行收回房屋到市场上抛售, 当房屋被大量抛售必然 导致房价下降, 次级债券紧跟着缩水变得不值钱, 而 一些借高利贷来买债券的公司也面临破产，保险公司
等金融机构也受到影响，从而金融危机爆发。

随着金融的发展, 金融所带来的福利也惠及我们 生活的方方面面, 给我们的生活带来了前所未有的便 利。然而, 当金融危机爆发时, 其破坏力不是我们能 够预料的, 尤其是在全球经济一体化的今天，当世界 经济连成一体时, 金融危机爆发很有可能演变成系统 性的金融危机，其持续性之长，破坏范围之广，对本 国经济的冲击是巨大的。因此, 研究别国经济危机, 可以从别国经济中看到自己存在的问题与不足, 从中 得到一点启示, 从而完善自身, 在本国的金融监管上 下功夫, 有利于避免金融危机的发生或者减少金融危 机发生时所带来的危害, 或者预料金融危机发生而提 
前想出的对策。对危机发生的原因进行分析, 有助于 金融危机理论的研究, 对金融危机领域做出一点点贡 献, 也为关于这方面的研究提供一点点思路或想法。

\section{2. 次贷危机产生的原因}

\section{1. 从金融机构来说}

次贷危机产生的一个原因是金融机构以损害他 人利益为前提赚取自己的收益, 例如以新世纪公司为 代表的贷款公司，在美国政府鼓励贷款公司向中低收 入人群发放贷款的背景下, 大量放贷给民众, 能够在 12 秒内确认是否贷款, 它的审核流程不严格甚至根本 没有审核, 即使明知道己经产生了资产泡沫, 还是无 视当时存在的问题大量贷款, 如此简单的程序为它带 来了可观的收入, 但它带来的后果却是由纳税人来承 担, 由政府用纳税人的钱来偿还, 受损最大的还是民 众。审核条件低、贷款的门槛低、买房的首付低, 以 致一些根本没有收入的人也能够贷款买房, 这就是次 级贷款, 所以民众都去买房了, 房价上涨, 从而形成 房地产市场的泡沫。

另一方面, 为了转嫁风险, 贷款机构从借款者处 获得房屋抵押产权, 又将抵押债权出售给投资银行, 投资银行通过创新金融衍生品来吸收资金, 将贷款合 同打包做成债券并支付高利息在资本市场上出售，而 这些产品的收益就由买房者的月供来支付。在这个过 程中, 评级机构扮演了一个重要的角色, 它将这些贷 款合同做成的债券评级, 分为三级, 最高评级为 AAA, 最差评级为 $\mathrm{BBB}$, 当 $\mathrm{BBB}$ 卖不出去时, 又将 $\mathrm{BBB}$ 分为 三个评级, 如此循环。看到回报率这么高且安全性相 当于国债的债券，对冲基金、银行、资产管理公司、 保险公司都竞相购买, 于是 AAA 评级的债券受到大量 投资者的青睐。但是本来这些贷款合同就是由次级贷 款而来, 将次级贷款加工形成次级债券, 违约率上升, 受影响的不止是美国的金融市场, 因为这些债券还有 其他国家的投资者购买, 亏损的是所有购买这些债券 的人。

除了以上所述的因素之外, 房利美和房地美也在 其中扮演了一个重要角色。房利美 (Fannie Mac) 和 房地美 (Freddie Mac) 是美国住房融资体系的核心, 为保证住房市场的资金流动由美国政府依法发起设 立的两大私营企业, 主要是通过银行等金融机构购买 住房抵押贷款并将其证券化，将其出售从而获利，而 银行也能发放更多的贷款，扩大房屋拥有人数。

2004 年, 次级贷款受到欢迎, 两房的经营模式也 被其他金融机构模仿, 许多次级贷款被打包成证券, 两房的市场地位受到威胁。恰好此时美国政府要求其 向中低收入者发放贷款，而公司的股东为追求高额利 润, 极力叫两房收购住房抵押贷款, 于是两房顺势而 为, 但银行要求其尽量收购高风险的贷款, 因此, 收 购的贷款大多是次级贷款。2005-2007 年间，两房拥 有的 AAA 级次贷最多, 这也为次贷形成规模在全世界
销售从而造成金融危机埋下了一个隐患。2006-2008 年间, 房利美收购和担保的高风险贷款是历年之最, 最高峰时, 占美国家庭住房抵押贷款市场份额的 40\%。 收购的高风险贷款就像一颗定时炸弹, 一旦违约坏帐 就接连产生。

两房能够如此大胆的购买大量次级贷款, 主要是 因为 “隐性担保”，投资者也陷入了一个误区，认为 两房担保的债券风险仅次于国债，并且出了问题有政 府担保。但债券缩水之后, 两房损失惨重, 房利美市 值由 2007 年底的 389 亿美元降到 100 亿美元, 房地 美的市值由 220 亿美元降到 50 亿美元, 在此情况下, 投资者对其未来预期下降，大量抛售债券，两房更是 雪上加霜。

有政府的支持，两房不用担忧风险问题，最终买 单的是纳税人, 利润是私有化的, 风险是社会化的, 两房的资产规模太大，因此美国经济受到严重影响。 另外, 两房利用金融创新工具将风险转移给美国及全 球投资者，大量投资者被迫卷入其中，从而风险扩散 到整个金融系统。金融创新越活跃，次贷风险扩散得 越广泛, 越深入。

\section{2 从国家层面来说}

\section{2. 1. 国家提倡“新自由主义”理论}

1945 年-1973 年, 美国实行的是管制的资本主义, 它的特征是政府要加强对经济的干预, 加大对宏观经 济的调控, 对金融系统实行严格的管制, 以及为保障 人民生活制定大量有利于民众的社会福利政策。它的 优点是在有政府管制的情况下市场不容易发生危机， 金融市场能够更加稳定。

然而在 80 年代后，这种管制的资本主义形式被 取代, “新自由主义”占主导地位, 这种资本主义形 式使得金融市场缺少监管，让市场自行调节，而政府 不再进行干预，市场由有节制的竞争变成自由、残酷 的竞争。

从历史上看, 美国 19 世纪实行的就是比较自由 的市场经济，大概每 10 就会产生一次严重的金融危 机，到 1929 年，迎来了美国的 “大萧条”，美国金融 体系崩溃。1945 年-1973 年实行的管制的资本主义, 而这期间没有发生过一次大的金融危机。但在 80 年 代实行 “新自由主义” 后就产生一系列的问题, 80 年 代, 监管机构对监管的放松, 大量银行机构破产倒闭, 造成经济金融系统紊乱。90 年代又产生了股票市场的 泡沫, 纳斯达克的估值非常高, 到 2000 年 3 月, 纳 斯达克泡沫破裂，股价暴跌。进入 21 世纪，又产生 了房地产泡沫。这些无一不说明金融市场的发展, 不 能只仅仅依靠市场自身运行, 还需要国家的宏观调控 相结合，只有 “看得见的手” 和 “看不见的手” 共同 作用于市场, 才能保证经济平稳运行。 


\subsection{2. 对金融产品及金融市场监管不到位}

美国坚持市场自律的原则, 市场自由化程度过高, 政府尽量少干预, 市场能做的事情就让市场做, 忽略 了政府在金融监管方面的责任, 但仅仅只依靠市场或 者政府去做, 事情往往不尽人意, 况且市场就是以利 益为中心, 利益最大化是其目标, 惟有将 “有形的手” 和“无形的手”结合起来, 才能为经济发展保驾护航, 因此, 次贷危机发生的一个重要原因是金融监管方面 的缺失。

纵观次贷危机的各个方面, 其实各个环节都存在 一些问题。第一, 银行和贷款机构没有考虑借款人是 否有足够的还款能力, 没有考虑自身的资产负债表和 是否会产生坏账就放贷, 所以, 这些贷款公司在发放 次级贷款时没有受到有效监管; 第二, 投资银行和基 金公司将次级贷款合同证券化并在资本市场上销售， 将在信贷市场的风险转移到了资本市场, 这个环节也 没有受到监管; 第三, 评级机构的评级过程也没有受 到监管, 在利益的驱使下, 评级机构只有努力用各种 方法提高信用等级才能吸引和留住客户。另一方面, 市场是时刻在变的, 数据更是瞬息万变, 在这样的条 件下, 评级机构无法及时更新数据模型, 只能用一些 历史数据和模型来评估, 一旦模型某个条件发生变化 就不能与现实情况相吻合, 无法适用。而投资者因为 信息不对成, 无法掌握充分全面的信息, 只能依赖评 级机构评估出来的信用等级来购买产品。但本就是由 次级贷款加工而来的次级债券, 再经过评级机构不准 确的评估, 购买债券的投资者就成了最后的风险承担 者, 当投资者受到大量亏损, 整个金融市场崩溃, 次 贷危机会发生也就不足为奇了; 第四, 对金融衍生品 缺乏监管。在交易规则、信息披露方面是金融衍生品 的一个监管真空地带, 没有受到监管当局的有效监管。 金融衍生产品的初衰就是为了规避风险, 但为了高额 的利润人们大量购买, 导致金融衍生品成为了促使次 贷危机爆发的催化剂。

从危机发生的全过程来看, 监管机构没能对其全 程进行监管, 在危机发生之前, 没有发出一个危险信 号, 且在危机发生后才采取救助措施, 缺乏有效监管, 在经济全球化的背景下, 次贷危机得以在全球迅速蔓 延。

\section{3. 次贷危机对我国金融监管的启示}

绿色信贷现今越来越受到世界各国的重视, 中国 也不例外, 随着经济的发展, 环境的变化, 绿色信贷 越来越重要。绿色信贷工作的开展对我国商业银行有 着重要的影响。

\section{1. 从居民的意识来说}

\section{1. 1. 居民个人}

美国次贷危机给我们的一个警告是, 无论在何种
情况下, 不以现实情况为依据, 过度消费、超前消费、 无节制消费都是不可取的。次贷危机正是由于美国居 民不顾自身经济状况，大量贷款消费，再加上储蓄率 低, 支出大于收入, 一旦贷款利率上调和房价下跌, 个人抵御风险的能力不足, 违约率上升, 信用危机就 此爆发。适度的超前消费是鼓励的, 但并不是说经济 完全由超前消费来主导变为一个消费型社会, 居民个 人要有一个 “量入为出, 适度消费” 的消费理念, 适 度提高储蓄率, 增强个人的风险安全意识。

\subsection{2. 政府引导}

除了居民个人需要加强自身防范风险的意识之 外, 还需要政府加以引导, 美国长期以来的超前消费 意识已经根深蒂固, 因此需要政府施以援手来转变其 消费意识, 政府应提倡和鼓励转变美国的消费方式, 使超前消费意识慢慢淡出人们的生活之中, 并将正确 的消费理念逐渐植入居民脑中, 使其有危机意识。生 于忧患, 死于安乐, 我们都该有一种忧患意识。

\section{2 从金融机构来说}

\subsection{1. 在审核方面}

金融机构在贷款前一定要把好关, 仔细评估借款 人的风险状况和信用状况, 是否有偿还能力, 并且贷 款审核的程序要严格执行, 审核条件不能太低, 但要 尽量简化。

\subsection{2. 在风险方面}

创新驱动发展, 创新是一个国家生机与活力的表 现。但在金融衍生产品的创新方面, 我们要更加谨慎, 高收益的同时必然伴随着高风险，况且，对于一个金 融机构来说, 防范风险是必做的事情, 无论身处的大 环境是好是坏，这是最基本的，一旦金融危机发生， 可能会演变为系统性金融危机, 金融体系就会运转失 灵, 导致社会经济秩序的混乱。因此, 要时刻谨记风 险与收益成正比。

金融机构在防范风险方面, 除了建立风险防控体 系外, 还可以从内部的员工入手, 每个环节都有关于 风险方面的评估标准，建立奖惩机制，提升员工的积 极性, 鼓励员工发现风险, 然后对这些风险进行评估 和分类, 哪些是可以忽略不计的, 哪些是必须要注意 的, 分出一个轻重缓急, 这样可以尽早发现风险, 将 其扼杀在摇篮之中。

\section{2. 3. 在道德方面}

在经济学中, 有一个观点是, 人是自私的, 是以 一个理性的经济人。不可否认, 人都是从自己的利益 角度出发, 但作为一个金融人, 我们应具备该有的职 业道德和社会道德。一味的追求利益, 最终损害的是 
自己的利益, 新世纪公司为追求高额利润, 给一些信 用状况不好，没有偿还能力的人放贷，如果还不上贷 款, 并且利息越积越高, 可能会导致一个家庭四分五 裂，像此次危机那样，最终新世纪公司也破产，如果 不放贷给他们，既是对他们负责也是对自己负责。

首先, 银行等放贷机构不能只注重扩张自己的信 贷业务而不顾潜在的风险, 虽然银行过度放款, 买房 的人多，资金投入到房地产市场，促进了房地产市场 的发展，银行业从中获利，但是也应该注意所发生的 交易是否会有产生坏账的危险, 这是银行最基本也是 必须要做的事。另外, 银行是国家收紧货币投放量的 一个途径, 如果银行能够把控好贷款的条件, 不给信 用低及无收入的人放贷, 也许就能避免借款人还不上 款导致危机发生的情况。

其次, 评级机构应当客观公正。评级公司不能为 了能够将产品卖出去而随意评估债券的风险, 而客户 找能将债券评级升高的评级机构来评估显得太过轻 率, 金融衍生产品应该经过多方评级, 将风险降低, 才不至于引发次贷危机。

最后，第三方金融机构也应当重视自身的责任。 投资银行等金融机构将次级贷款打包成次级债券, 没 有考虑到一旦公众买了如此高风险的产品会受到怎 样的损失，应该做到自身和公众能达到双赢的结果， 最起码不能损害公众的利益, 只看见当下的利益, 而 没有注意到长远的发展。

\section{3 从监管当局来说}

监管者对金融衍生产品监管不力是此次危机发 生不可避免的原因, 自《商品期货现代化法》颁布后, 监管者对金融衍生产品就放松了监管，导致以投资银 行为代表的金融机构对次级贷款进行创新, 从而次级 债券诞生, 而危机也由此进行扩散。它所带来的积极 影响是不可否认的, 但是其风险是更为集中和隐蔽的, 随着经济一体化的发展, 风险更是在全球范围内转移。 所以不能让金融衍生产品这一板块处于监管真空地 带, 监管者应提高自身的执行力, 增强自身的职能, 并且建立一个合作机制, 确保危机发生时能够迅速反 应, 反应及时灵敏, 措施到位, 应提高金融衍生产品 信息的透明度，使金融衍生品处于监管当局的监控之 下, 投资者也不至于只能依靠评级机构的评级而盲目 投资, 由此风险必将下降。除此之外, 还要适当的加 强政府对经济的干预, 不能一味的让市场自行调节, 要加强政府对银行放贷和市场的管理。

\section{4. 结论}

次贷危机对各国的影响都是深远的, 我国当然不 能幸免于难受到波及。我们可以以次贷危机为例, 以 史为鉴，反省自身，从中获得一些经验或教训，再采 取措施对危机进行规避，才能在经济全球化的背景下 迎接挑战，促进我国经济更快更稳的发展。通过以上 的分析, 我们可以从中得出以下结论。

第一, 消费方式要以实体经济为基础。此次危机 中, 利率连续下降使得房地产市场繁荣, 但次级抵押 贷款市场对利率较为敏感, 利率上调, 借款者还不上 款, 房地产泡沫破灭, 银行收回房屋, 房屋贬值缩水, 一些企业开始破产，这一过程其实是一场信用危机， 由借款人违约造成。由此可知, 我们的消费要建立在 实体经济的基础上，虚拟经济风险非常大。

第二, 要对金融衍生品创新进行监管。美国当时 的经济发展太迅速，而金融监管远落后于衍生品创新 的速度, 衍生品缺乏有效监管就埋下了风险隐患, 随 后投资银行、保险公司、资产管理公司这些金融机构 就接连破产，危机爆发的速度就呈几何态势增长。

最后，我国从中得到的启示。如今全球处于一个 人类命运共同体，“牵一发而动全身” 的时代，机遇 与挑战并存, 在经济上, 我们要慎之又慎, 尤其是金 融衍生品这方面要加强监管, 从次贷危机中吸取教训, 进一步调整我国的经济结构, 转变经济发展方式, 拉 动消费，促进我国经济稳中向好发展。

\section{REFERENCES}

[1] Allen, Franklin, Douglas Gale. Comparing Financial Systems[M]. Cambridge,London: The MIT Press, 2000.

[2] Candace Edmonds. The Dodd-Frank Act Rulemaking Coordination and Impact of Rules [M]. New York: Nova Science Publishers,2013.

[3] Jeffrey R. Holman. The State of Community Banks and Credit Unions and the: Potential Role of the Dodd-Frank Act[M]. New York: Nova Science Publishers, 2013.

[4] Barth,James R.,Gerard Caprio Jr.,Ross Levine. Rethinking Bank Regulation: Till Angels Goven[M]. New York: Cambridge University Press, 2006 . 